\title{
Development of Superconducting Combined Function Magnets for the Proton Transport Line for the J-PARC Neutrino Experiment
}

T. Nakamoto, Y. Ajima, Y. Fujii, N. Higashi, A. Ichikawa, N. Kimura, T. Kobayashi, Y. Makida, T. Ogitsu, H. Ohhata, T. Okamura, K. Sasaki, M. Takasaki, K. Tanaka, A. Terashima, T. Tomaru, A. Yamamoto (KEK) M. Anerella, G. Ganetis, R. Gupta, M. Harrison, A. Jain, J. Muratore,

B. Parker, P. Wanderer (BNL)

T. Obana (Graduate University for Advanced Studies)

T. Fujii, E. Hashiguchi, T. Kanahara, T. Orikasa (TOSHIBA)

May 16, 2005

Superconducting Magnet Division

Brookhaven National Laboratory

Operated by

Brookhaven Science Associates

Upton, NY 11973 


\section{DISCLAIMER}

This report was prepared as an account of work sponsored by an agency of the United States Government. Neither the United States Government nor any agency thereof, nor any of their employees, nor any of their contractors, subcontractors or their employees, makes any warranty, express or implied, or assumes any legal liability or responsibility for the accuracy, completeness, or any third party's use or the results of such use of any information, apparatus, product, or process disclosed, or represents that its use would not infringe privately owned rights. Reference herein to any specific commercial product, process, or service by trade name, trademark, manufacturer, or otherwise, does not necessary constitute or imply its endorsement, recommendation, or favoring by the United States Government or any agency thereof or its contractors or subcontractors. The views and opinions of authors expresses herein do not necessarily state to reflect those of the United States Government or any agency thereof. 


\title{
DEVELOPMENT OF SUPERCONDUCTING COMBINED FUNCTION MAGNETS FOR THE PROTON TRANSPORT LINE FOR THE J-PARC NEUTRINO EXPERIMENT
}

\author{
T. Nakamoto*, Y. Ajima, Y. Fujii, N. Higashi, A. Ichikawa, N. Kimura, T. Kobayashi, Y. Makida, \\ T. Ogitsu, H. Ohhata, T. Okamura, K. Sasaki, M. Takasaki, K. Tanaka, A. Terashima, T. Tomaru, \\ A. Yamamoto, KEK, Tsukuba, Japan
M. Anerella, G. Ganetis, R. Gupta, M. Harrison, A. Jain, J. Muratore, B. Parker, P. Wanderer, BNL, Upton, NY 11973, U.S.A.

T. Obana, The Graduate University for Advanced Studies, Tsukuba, Japan

T. Fujii, E. Hashiguchi, T. Kanahara, T. Orikasa, TOSHIBA, Yokohama, Japan

\begin{abstract}
Superconducting combined function magnets will be utilized for the $50 \mathrm{GeV}, 750 \mathrm{~kW}$ proton beam line for the J-PARC neutrino experiment. The magnet is designed to provide a dipole field of $2.6 \mathrm{~T}$ combined with a quadrupole field of $19 \mathrm{~T} / \mathrm{m}$ in a coil aperture of $173.4 \mathrm{~mm}$ at a nominal current of $7345 \mathrm{~A}$. Two full-scale prototype magnets to verify the magnet performance were successfully developed. The first prototype experienced no training quench during the excitation test and good field quality was confirmed.
\end{abstract}

\section{INTRODUCTION}

A second generation of long-baseline neutrino oscillation experiments has been proposed as one of the main projects at the J-PARC [1], [2] and the construction of the facility is in progress. Superconducting combined function magnets, SCFMs, will be utilized for the $50 \mathrm{GeV}$, $750 \mathrm{~kW}$ proton beam line for the neutrino experiment. The magnet is designed to provide a dipole field of $2.6 \mathrm{~T}$ combined with a quadrupole field of $19 \mathrm{~T} / \mathrm{m}$ in a coil aperture of $173.4 \mathrm{~mm}$ at a nominal current of $7345 \mathrm{~A}$. A series of 28 magnets in the beam line will be operated DC in supercritical helium cooling below $5 \mathrm{~K}$ [3]. Since the main accelerator will be operated at $40 \mathrm{GeV}$ in the beginning, the SCFM was designed for proton beam energies of 40 and $50 \mathrm{GeV}$. A cross sectional view of the SCFM is shown in Fig. 1 and the main design parameters are listed in Table $\mathbf{1}$.

Prior to the fabrication of production magnets, an R\&D program to build two full-scale prototype magnets was started to confirm the magnet design, fabrication tools and assembly procedures. The first prototype was built inhouse at KEK and was fully instrumented with voltage taps, quench-inducing heaters, capacitive gages, and strain gages to investigate quench and mechanical behaviors. In contrast, the purpose of the second prototype was the technology transfer to an industrial company and verification that the manufacturing process

tatsushinakamoto@kek.jp

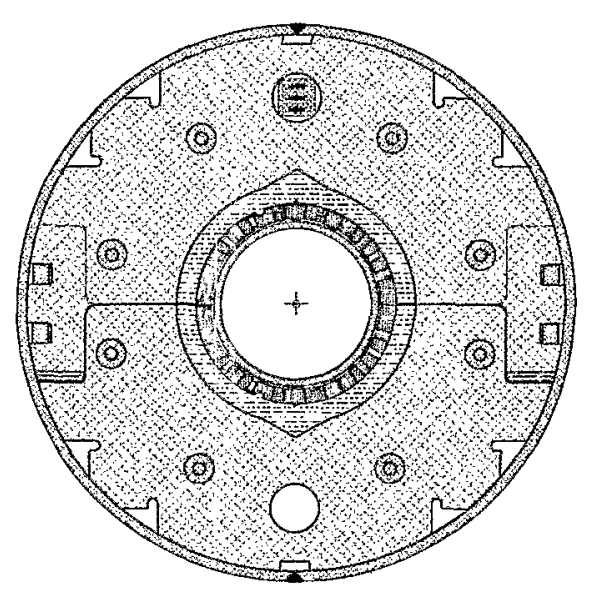

Figure 1: Cross sectional view of the superconducting combined function magnet, SCFM, for the $50 \mathrm{GeV}$ proton beam line for the J-PARC neutrino experiment.

is reproducible. According to the bidding, the contract was awarded to Toshiba and the second prototype was fabricated at the site of KEK by using the same tools provided for the first prototype.

Quench protection heaters were additionally installed in the second prototype while the first one had no protection heaters: test results of the first prototype and recent numerical simulations indicated that the magnet needed to have the quench protection heaters, as explained in this paper. Whereas the second prototype contained an ordinary beam tube the same as the production magnets, a model beam tube with a corrector coil supplied by BNL was installed in the first prototype. Initially, the corrector coil was designed to be wound on the beam tube inside the main magnet but the recent beam optics design changed the specifications so that the corrector magnet will now be located in an inter-connect region between the cryostats. 
So far, two prototype magnets have been successfully completed. The first prototype was tested at $4.4 \mathrm{~K}$ to evaluate quench characteristics and magnetic field. The second prototype is being prepared for the cold excitation test.

\section{DESIGN AND FABRICATION}

As the detailed magnet design and the fabrication process has been reported in the previous papers [4], [5], this summary concentrates on the most important aspects.

\section{Design Overview}

A unique feature of the SCFM is the left-right asymmetry of the coil cross section: current distributions for superimposed dipole- and quadrupole- fields are

Table 1: Main Design Parameters for the SCFM

\begin{tabular}{|c|c|}
\hline Magnet* & \\
\hline Physical \& Mag. Length & $3630 \& 3300 \mathrm{~mm}$ \\
\hline Coil In. \& Out. Diameter & $173.4 \& 204.0 \mathrm{~mm}$ \\
\hline Yoke In. \& Out. Diameter & $244 \& 550 \mathrm{~mm}$ \\
\hline Shell Outer Diameter & $570 \mathrm{~mm}$ \\
\hline Dipole \& Quad. Field & $2.59 \mathrm{~T} \& 18.7 \mathrm{~T} / \mathrm{m}$ \\
\hline Coil Peak Field & $4.7 \mathrm{~T}$ \\
\hline Load Line Ratio & $72 \%$ \\
\hline Operational Current & $7345 \mathrm{~A}$ \\
\hline Inductance \& Stored Energy & $14.3 \mathrm{mH} \& 386 \mathrm{~kJ}$ \\
\hline \multicolumn{2}{|l|}{ Number of Turns } \\
\hline Left side: 2 Blocks & 35,6 \\
\hline Right side: 5 Blocks & $6,5,10,13,7$ \\
\hline \multicolumn{2}{|l|}{ Mag. Force of a single coil } \\
\hline \multirow[t]{2}{*}{$\Sigma F x \& \Sigma F y$} & $-618 \&-360 \mathrm{kN} / \mathrm{m}$ \\
\hline & $434 \& 114 \mathrm{kN} / \mathrm{m}$ \\
\hline \multicolumn{2}{|l|}{ Superconducting Strand } \\
\hline Diameter \& Twist Pitch, Z & $0.825 \mathrm{~mm} \& 15 \mathrm{~mm}$ \\
\hline Cu/SC Ratio & 1.95 \\
\hline Filament Diameter & $6 \mathrm{~mm}$ \\
\hline \multicolumn{2}{|l|}{ Superconducting Cable } \\
\hline Width \& Middle Thickness & $15.1 \mathrm{~mm} \& 1.480 \mathrm{~mm}$ \\
\hline Keystone Angle & $0.9^{\circ}$ \\
\hline $\mathrm{RRR}$ of $\mathrm{Cu}$ & $>70$ \\
\hline Cabling Pitch, S & $100 \mathrm{~mm}$ \\
\hline Number of Strands & 36 \\
\hline Critical Current & >12240A@6 T,4.2 K \\
\hline
\end{tabular}

"Design parameters at $50 \mathrm{GeV}$ are listed. combined in a single layer coil. Another design feature is the adoption of glass-fiber reinforced phenolic plastic spacers for electrical insulation to reduce the labor and inspection costs.

The most appropriate 2D coil arrangement to generate the required field was determined by using ROXIE [6]. As shown in Fig. 1, the coil is divided into 2 blocks for the left (high field, HF) side and 5 blocks for the right (low field, LF) side to provide the appropriate combined field. The effective pole is rotated by about $20^{\circ}$ towards the high field side (left side in this figure). The shape of the coil ends was also modelled by ROXIE, which provided $\mathrm{CNC}$ files for the manufacture of $\mathrm{G} 10$ end spacers.

The 3D magnetic field was calculated by using Opera$3 D$ (TOSCA). The magnetic length was calculated to be $3350 \mathrm{~mm}$ for the dipole field. The relatively larger value of $B_{3}$ was mainly produced by the shape of the coil ends and cannot be eliminated. Beam optics calculations confirmed that the design magnetic field of the SCFM within a tolerance of $10^{-3}$ at a reference radius of $50 \mathrm{~mm}$ was sufficiently acceptable,

The coil is mechanically supported by a keyed yoke made of fine-blanked iron laminations. The iron yoke also functions as a magnetic flux return. The plastic spacers are placed between the coil and the iron yoke. The coil pre-stress of $80 \mathrm{MPa}$ is produced by the yoking process. Both coil ends are longitudinally fixed by end plates.

\section{Coil Winding}

The Rutherford type $\mathrm{NbTi} / \mathrm{Cu}$ superconducting cable that was used for the outer layer of the LHC main dipole magnet was simply adopted for the SCFM to reduce the cost for cable development. The insulation was, however, changed to a double layer of Upilex-RN tape with B-stage epoxy resin that was used in the MQXA magnets for the LHC insertion regions [7]. While the end spacers and the ramp box for the lead transition were made of $\mathrm{G} 10$, the wedges and the shim at the straight section were made of G11. They were precisely made by CNC machining. Size control of the wedges was very important to achieve good field quality and adequate pre-stress. The tolerance of the wedge size was set to be 0.1 ' $\mathrm{mm}$.

The coil was wound like a dipole coil and cured in a forming block at about $400 \mathrm{~K}$ for 5 hours. An appropriate combination of several shims for the curing was carefully chosen to achieve the design coil stress of $80 \mathrm{MPa}$ during yoking and to avoid displacement of the effective pole due to unbalanced coil sizes. The shims were inserted between jigs and on the median plane of the coil at the curing so that the asymmetric coil over-size was correctly controlled.

The azimuthal coil sizes at the low- and high-field sides for two prototypes were checked before the magnet assembly. The relative coil sizes are shown in Fig. 2 as a function of the azimuthal stress. In this figure the coil size at the median plane was defined to be $0 \mathrm{~mm}$. Both sides of the coils showed consistent mechanical behaviour. The coil pre-stress after magnet assembly was expected to be 


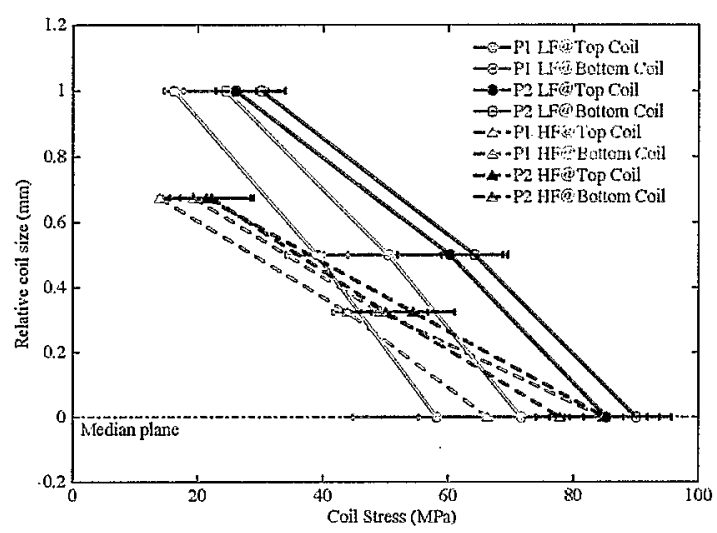

Figure 2: Relative coil size for two prototypes as a function of azimuthal coil stress. Error bars indicate the standard deviation: each measurement was made at 4 positions along the coil.

60 to $90 \mathrm{MPa}$ and was within the acceptable range for the manufacturing specification set by a mechanical study with a short coil section [5].

\section{Yoking}

A picture of the magnet to be prepared for the yoking process is shown in Fig. 3. The glass-fiber reinforced phenolic plastic spacers were placed between the coil and the iron yoke. The plastic spacers function as not only electrical insulation but also to align the coil with respect to the iron yoke: a triangular feature at the top fits into the notch of the iron yoke and a circular shaped key on the inner diameter fits into the groove on the pole spacer of the coil, as shown in Fig. 1.

The keyed iron yoke technology was transferred from the MQXA [7]. The "fixing yoke" sheet was $5.8 \mathrm{~mm}$ thick and had grooves for keying at claws on both sides while the "spacer yoke" sheet $6.0 \mathrm{~mm}$ thick had no claw. The upper- and lower- yoke assemblies were compressed at their shoulders up to about $13 \mathrm{MN}$ by the hydraulic press and were locked by keying. The yoke gap was closed at the median plane by the keying. With the keys installed, the cross sectional mechanical structure and the coil alignment with an appropriate pre-stress were

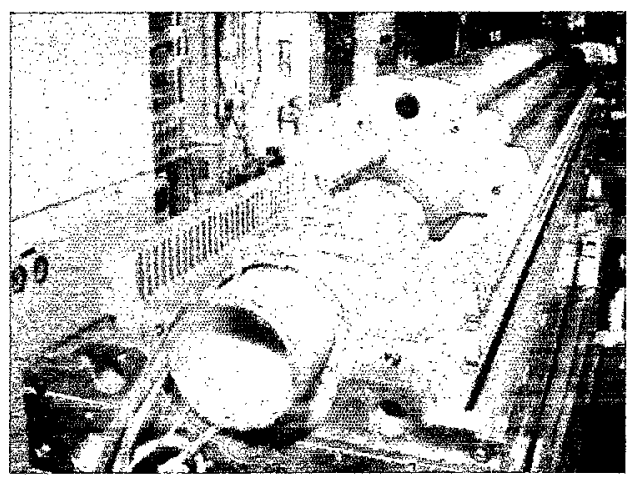

Figure 3: Magnet to be prepared for the yoking process.

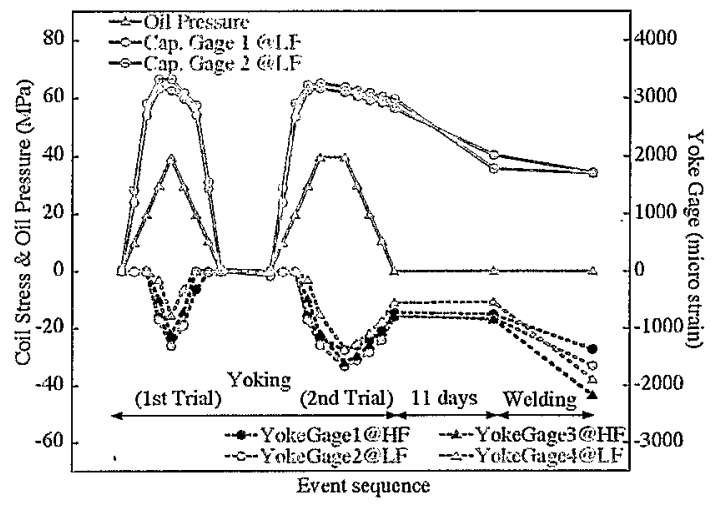

Figure 4: Coil stress and yoke gap closure during the first prototype magnet assembly.

accomplished.

Figure 4 shows trend data of the azimuthal coil stress and the yoke gap closure of the first prototype during the magnet assembly. The coil stress was measured by 2 capacitive gages installed between the top- and the bottom- coils in the low field side. The yoke gap closure was monitored by 4 sets of strain gages located at the mating point of the iron yoke. As shown in Fig. 4, negative values of the yoke strain gages proved that compressive force at the mating point was generated and the gap was completely closed. Right after the yoking, a coil stress of about $60 \mathrm{MPa}$ was obtained. This result was consistent with the predictions by the coil size measurement shown in Fig. 2. The coil stress eventually decreased to about $35 \mathrm{MPa}$, although the yoked magnet was radially tightened by the shell welding. It was possibly caused by a creep effect of the coil and/or the capacitive gages under a high stress of long duration.

The dimensions of the yoked magnet were measured and it was found that the vertical yoke diameter was $0.25 \mathrm{~mm}$ larger than the horizontal one: the magnet cross section was ovally deformed due to the horizontal split keyed yoke structure, as similarly observed in the MQXA.

\section{Shell Welding and Ends Work}

The helium vessel was formed by two halves of an SUS304L shell covering the yoked magnet. The shell had 4 holes at 5 points along the magnet length, 20 holes in total. The yoked magnet was rotated $90^{\circ}$ and the top and bottom were longitudinally welded by 2 automatic welding machines as the yoke shoulder was aligned through the holes by the hydraulic press. A backing strip was not permitted for the shell welding by Japanese highpressure regulation. Instead, pre-formed inserts of SUS308L were set between two halves of the shell and were completely welded at the first welding pass. Shell welding needed 11 passes in total. The horizontal and vertical straightness of the two prototypes after the shell welding were measured with respect to the yoke shoulder by using a Laser Tracker and are shown in Fig. 5. For each magnet, the straightness in the upside down position 


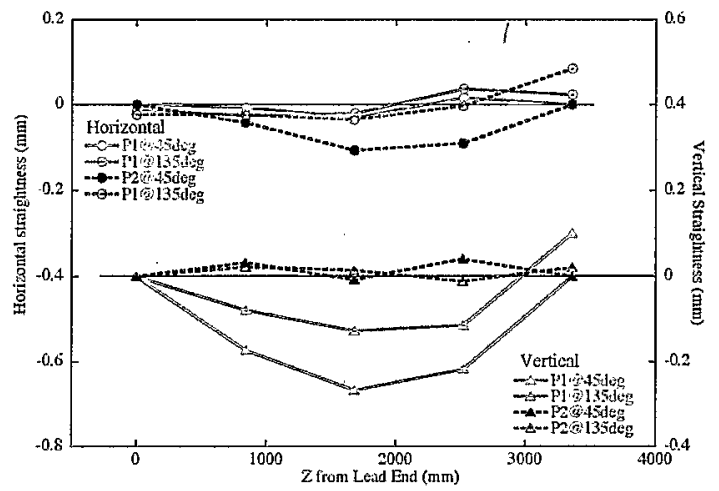

Figure 5: Straightness of two prototypes.

was also surveyed and the results were confirmed to be consistent with the normal position. The first prototype showed a relatively large vertical sag of $0.2 \mathrm{~mm}$ compared with the second one. However, the straightness of both magnets was much better than the required.

Fifteen alignment targets were precisely fixed on the shell at 0,90 , and $180^{\circ}$ with respect to the yoke shoulder and then all holes were welded over with caps. The targets are used for the magnet alignment in the following process.

Ferrules of SUS304L, so called "end-rings", transversely welded at both ends of the shell functioned to fix the end plates. Each coil end was longitudinally compressed about $40 \mathrm{kN}$ by studs on the end plates. Leads from the top- and bottom- coils were connected by using $96 \mathrm{Sn}-4 \mathrm{Ag}$ solder with a non-activated flux of Kester \#135 and then the lead spice was contained in a G10 case fixed to the end plate. The completed prototype magnet is shown in Fig. 6.

\section{TEST RESULTS}

The first prototype was inserted into a $9 \mathrm{~m}$ deep vertical cryostat and was tested in liquid helium at $4.2 \mathrm{~K}$ to evaluate the performance. Two series of cold tests with a thermal cycle to/from room temperature were carried out.

\section{Quench Characteristics}

After several shutoffs of a power supply at certain currents to check a whole system, the first prototype was energized with a ramp rate of $5 \mathrm{~A} / \mathrm{s}$ and reached to the nominal current of $7345 \mathrm{~A}$ without a spontaneous training quench. Next, the magnet was successfully excited up to $7700 \mathrm{~A}$. The magnet was also energized to the nominal current with different ramp rates and no quench occurred even at the maximum ramp rate of $1000 \mathrm{~A} / \mathrm{s}$ that corresponded to the limit of the power supply. The magnet was excited during the second cold test but there was no training quench. In fact, the magnet has not experienced a training quench. Thus, the magnet quench performance has been excellent.

A number of spot heater quench tests was carried out to measure the normal zone propagation velocity and the resistive voltage rise during a quench. These were crucial

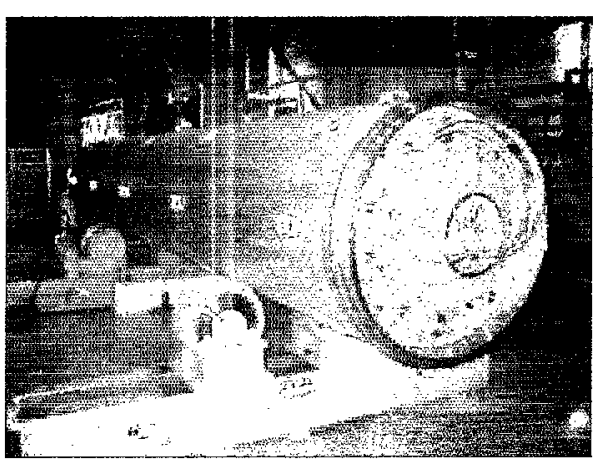

Figure 6: Completion of the second prototype.

for the quench protection study. The heaters, mounted on a single superconducting cable at different positions such as the coil blocks in the high- and low-field sides and the lead at the median plane, were fired to induce the quenches. Quench detector balance signals for the heater quenches at a current of $7345 \mathrm{~A}$ are exhibited in Fig. 7. Lines without symbols are computation results of the coil resistive voltage. In the present powering scheme, the SCFMs will be energized in series and each magnet will be protected by a cold diode whose on-voltage at $4.2 \mathrm{~K}$ is around $6 \mathrm{~V}$. The acceptable time delay between quench initiation and the start of current bypassing is estimated to be at most $0.15 \mathrm{sec}$. As shown in Fig. 7, all voltage rises are much slower. Especially at lower field, the voltage requires much more than $0.25 \mathrm{sec}$ to reach $6 \mathrm{~V}$. This could lead to serious damage of the coil. While the calculation reproduces the experiment quite well at the high field quench, the calculation significantly overestimates the experiment at the lower field quenches. Even with this optimistic calculation, the maximum coil temperature during a quench is estimated to be around $700 \mathrm{~K}$, too high to be withstood by superconducting cable. The normal zone propagation velocities were determined in the same heater quenches by using voltage taps. The velocities were much lower than our expectations and the results were consistent with the voltage rise measurement.

Therefore, we judged that the SCFM needed to have quench protection heaters and installed the heaters into the second prototype for the protection study. The heaters were designed to be set on the high field side adjacent to the ramp box and to initiate quenches in multiple turns of the coil so that the resistive voltage rapidly increases to the on-voltage of the cold diode. The computation predicts the maximum coil temperature below $350 \mathrm{~K}$ even for a quench at the lowest field.

\section{Field Quality}

Magnetic field measurements were performed with a $500 \mathrm{~mm}$-long rotating printed circuit board on which 5 radial rectangular coils were arranged in parallel. The rotating board was vertically scanned along the magnet in the warm-bore tube. Analogue bucking with a combination of the radial coils was adopted to obtain higher order harmonics. In this measurement system, it is 


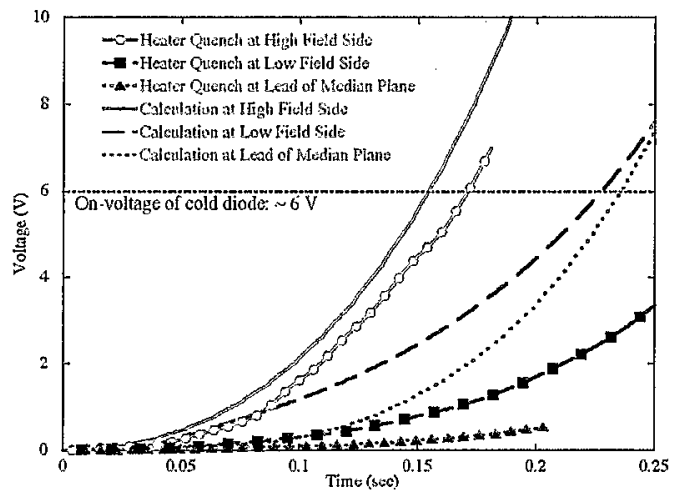

Figure 7: Quench detector balance signals from spot heater-induced quenches at $7345 \mathrm{~A}$.

difficult to determine the dipole field with good accuracy because an off-centered rotating axis induces a "feeddown" effect from higher order harmonics. This significantly affects measurement of the dipole field because of the large magnitude of the quadrupole field. In the following data, therefore, the magnetic field was analyzed so that average of the skew quadrupole component along the magnet straight section was equal to zero.

Dipole and quadrupole components at the magnet center at the current of $7460 \mathrm{~A}$ were determined to be $2.68 \mathrm{~T}$ and $19.0 \mathrm{~T} / \mathrm{m}$, respectively, while the computations by ROXIE were $2.63 \mathrm{~T}$ and $19.0 \mathrm{~T} / \mathrm{m}$. The measurement was also made at the lower current of 5921 A to check the field for the $40 \mathrm{GeV}$ proton beam. The measured dipole and quadrupole components were $2.14 \mathrm{~T}$ and $15.2 \mathrm{~T} / \mathrm{m}$, respectively, while the calculations predicted $2.10 \mathrm{~T}$ and 15.3 T/m. Discrepancies on the dipole field between the measurement and the calculation were probably caused by the "feed-down" effects as mentioned above. Table 2 lists field integrals of harmonics. In this table, fields at a reference radius of $50 \mathrm{~mm}$ are listed. A large $B_{3}$ caused by the shape of the coil ends was measured as we expected. Generally, the measured values for higher order harmonics agree with the calculations by Opera-3D (TOSCA). It was confirmed that the field quality of the first prototype met specifications.

\section{SUMMARY AND FURTHER PLAN}

Two full-scale prototypes of the SCFM for the J-PARC neutrino experiment were successfully developed by KEK. The first prototype was tested and experienced no spontaneous quench. However, the test revealed that quench protection heaters should be installed in the magnet. The magnetic field of the first prototype was measured by the vertical measurement system and the good field quality was verified. The second prototype will be tested soon.

The construction will be started in 2005 and the entire system needs to be ready for the first beam extraction in 2009.
Table 2: Integral of Normal Term of Higher Order Harmonics.

\begin{tabular}{|lll|}
\hline & Measurement & Computation \\
\hline Current $(\mathrm{A})$ & 7460 & 7345 \\
\hline$B_{1}(\mathrm{~T} \cdot \mathrm{m})$ & 8.906 & 8.712 \\
\hline$B_{2}(\mathrm{~T} \cdot \mathrm{m})$ & 3.127 & 3.120 \\
\hline$B_{3}(\mathrm{~T} \cdot \mathrm{m})$ & $-220.6 * 10^{-4}$ & $-293.6^{*} 10^{-4}$ \\
$B_{4}(\mathrm{~T} \cdot \mathrm{m})$ & $-5.9 * 10^{-4}$ & $-20.1 * 10^{4}$ \\
$B_{5}(\mathrm{~T} \cdot \mathrm{m})$ & $-51.9 * 10^{-4}$ & $-30.6^{*} 10^{4}$ \\
$B_{6}(\mathrm{~T} \cdot \mathrm{m})$ & $-75.2 * 10^{4}$ & $-62.8 * 10^{-4}$ \\
$B_{7}(\mathrm{~T} \cdot \mathrm{m})$ & $-44.6^{*} 10^{-4}$ & $-20.9^{*} 10^{-4}$ \\
$B_{8}(\mathrm{~T} \cdot \mathrm{m})$ & $-74.5^{*} 10^{-4}$ & $-32.0^{*} 10^{-4}$ \\
$B_{9}(\mathrm{~T} \cdot \mathrm{m})$ & $-79.9 * 10^{4}$ & $-73.4^{*} 10^{-4}$ \\
$B_{10}(\mathrm{~T} \cdot \mathrm{m})$ & $-13.8 * 10^{-4}$ & $-0.3 * 10^{-4}$ \\
$B_{11}(\mathrm{~T} \bullet \mathrm{m})$ & $-10.9 * 10^{4}$ & $-25.5^{*} 10^{4}$ \\
$B_{12}(\mathrm{~T} \bullet \mathrm{m})$ & $18.9 * 10^{-4}$ & $16.6^{*} 10^{-4}$ \\
\hline
\end{tabular}

\section{REFERENCES}

[1] Y. Itow et. al., "The JHF-Kamioka neutrino project," hep-ex/0106019.

[2] M. Furusaka et. al., "The joint project for highintensity proton accelerators," KEK Report 99-1; JAERI-Tech 99-O56; JHF-99-3, 1999.

[3] T. Ogitsu et. al., "Superconducting magnet system at the $50 \mathrm{GeV}$ proton beam line for the J-PARC neutrino experiment," IEEE Trans. Appl. Superconduct., vol. 14, no. 2, pp. 604-607, 2004.

[4] T. Nakamoto et. al., "Design of superconducting combined function magnets at the $50 \mathrm{GeV}$ proton beam line for the J-PARC neutrino experiment," IEEE Trans. Appl. Superconduct., vol. 14, no. 2, pp. 616-619, 2004.

[5] T. Nakamoto et. al., "Development of a Prototype of Superconducting Combined Function Magnet for the $50 \mathrm{GeV}$ Proton Beam Line for the J-PARC Neutrino Experiment," to be published in IEEE Trans. Appl. Superconduct., vol. 15, 2005.

[6] S. Russenschuck, "ROXIE: routine for the optimization of magnet $\mathrm{X}$-sections, inverse field calculation and coil end design," CERN 99-01, 1999.

[7] T. Nakamoto et. al., "Production and performance of the LHC interaction region quadrupoles at KEK," IEEE Trans. Appl. Superconduct., vol. 13, no. 2, pp. 1321-1324, 2003. 